\title{
User Acceptance of Electronic Medical Record System: Implementation at Marie Stopes International, Myanmar
}

\author{
Win Min Thit ${ }^{1, *}$, Sai Wai Yan Myint Thu ${ }^{1, *}$, Jaranit Kaewkungwal ${ }^{1,2}$, Ngamphol Soonthornworasiri ${ }^{1}$, \\ Nawanan Theera-Ampornpunt ${ }^{3}$, Boonchai Kijsanayotin ${ }^{4}$, Saranath Lawpoolsri ${ }^{1,2}$, Sid Naing ${ }^{5}$, \\ Wirichada Pan-ngum ${ }^{1,6}$ \\ 'Department of Tropical Hygiene (Biomedical and Health Informatics), Faculty of Tropical Medicine, Mahidol University, Thailand \\ ${ }^{2}$ Center of Excellence for Biomedical and Public Health Informatics (BIOPHICS), Faculty of Tropical Medicine, Mahidol University, Thailand \\ ${ }^{3}$ Faculty of Medicine, Ramathibodi Hospital, Mahidol University, Thailand \\ ${ }^{4}$ Health Systems Research Institute, Ministry of Public Health, Nonthaburi, Thailand \\ ${ }^{5}$ Marie Stopes International Myanmar (MSI-M), Yangon, Myanmar \\ ${ }^{6}$ Mahidol-Oxford Tropical Medicine Research Unit, Faculty of Tropical Medicine, Mahidol University, Bangkok, Thailand
}

Objectives: This study assessed the technical feasibility and aimed to determine the factors influencing intention to use Electronic Medical Records (EMRs) at Marie Stopes International, Myanmar (MSI-M). Methods: A cross-sectional survey was conducted among 112 participants who were working at the clinics and head office of MSI-M. Demographic information, type of office, technical feasibility, information communication technology knowledge, computer usage, and user acceptance towards the proposed system were obtained from the participants. Results: The results indicated low health information technology usage and network availability at MSI-M clinics. Positive perception of EMRs was found among the staff members of MSI-M, which was reflected by positive responses regarding perceived usefulness (average score of 4.15), perceived ease of use (average score of 4.03), and intention to use (average score of 4.10) on a 5-point Likert scale. Statistically, staff from the head office expressed less desire to implement an EMR system (odds ratio $=0.07 ; 95 \%$ confidence interval, 0.01 0.97 ), especially when they do not perceive the usefulness of the system (odds ratio $=5.05$; $95 \%$ confidence interval, 2.39 10.69). Conclusions: Since health information technology usage and network availability were low in MSI-M, it is important to strengthen the information and communication technology infrastructure and introduce a policy for capacity building at MSI-M. Adequate training and strong leadership support are recommended for the successful initial implementation and sustainability of an EMR system at MSI-M.

Keywords: Electronic Medical Records, Myanmar, Non-Governmental Organization, Feasibility Study

Submitted: March 17, 2020

Revised: July 11, 2020

Accepted: July 20, 2020

\section{Corresponding Author}

Wirichada Pan-ngum

Department of Tropical Hygiene, Faculty of Tropical Medicine, Mahidol University, 420/6 Ratchawithi Road, Rajvithi, Bangkok 10400, Thailand. Tel: +66-2306-9188, E-mail: wirichada.pan@mahidol.ac.th (https://orcid.org/0000-0002-9839-5359)

*These two authors contributed equally to this work.

This is an Open Access article distributed under the terms of the Creative Commons Attribution Non-Commercial License (http://creativecommons.org/licenses/by-nc/4.0/) which permits unrestricted non-commercial use, distribution, and reproduction in any medium, provided the original work is properly cited.

(C) 2020 The Korean Society of Medical Informatics 


\section{Introduction}

Electronic Medical Record (EMR) systems have been rapidly implemented in the hospitals and clinics of high-income countries [1,2]. An EMR has been defined as "an electronic record of health-related information on an individual that can be created, gathered, managed, and consulted by authorized clinicians and staff within one healthcare organization" [3]. Implementation of an EMR system enables healthcare providers to improve the quality of care [4], provide positive financial return [5], easily read documentation in real time [5], save storage space [6], reduce medical errors [4], and analyze patients' information effectively [7]. On the other hand, changing from a paper-based system to an electronic system has been challenging in both developed and developing countries due to several obstacles, such as the high cost of initial implementation [8], technical concerns [8], resistance to change [8], sustainability of the Electronic Health Record (EHR) system [9], and confidentiality of patient data [9].

In Myanmar, the use of paper-based medical records is a common practice in the hospitals and clinics. Thus, healthcare service providers cannot track patients over time, and targeted overall quality of care cannot be achieved. The introduction of EMR systems could help to improve the efficiency and quality of care in developing countries [10]. Marie Stopes International, a UK-based international nongovernmental organization (INGO), is one of the largest international family planning organizations in the world [11]. It has been working in Myanmar to provide health services since 1998, and it has 25 clinics across the country. Keeping patient records in the paper-based format is common in Marie Stopes International Myanmar (MSI-M) clinics. In addition, patient information is collected and kept in three places: the clinic record card, the registration record at the clinic, and the clinic record booklet, which is given to the patient.

The use of EMR systems is vital to improve patient care, and yet it is not a common practice in hospitals/clinics in Myanmar. In addition, little is known about whether it is feasible within the current resource context to implement an EMR system in an INGO providing healthcare in Myanmar because no study has been conducted in the sector. In principle, information technology is used to enhance employee performance, and yet the benefits derived from the technology are often lost due to users' unwillingness to accept and use the information system. Thus, the objectives of this study were the following: (1) to assess the technical feasibility of implementing a new EMR system, and (2) to examine the factors that may influence the intention to use EMRs in the MSI-M clinics based on the technology acceptance model (TAM), with an extension to consider various demographic characteristics, including age, education, position held, computer usage, and information communications technology (ICT) knowledge. Knowledge gained from this study on the readiness of the proposed system from the organizational level down to the individual level will be a key to the future organization's strategic planning and decision-making regarding the initial implementation of an EMR system in MSI-M clinics.

\section{Methods}

\section{Study Population}

A cross-sectional survey was conducted in the head office and another 13 out of 25 MSI-M clinics from the Yangon region, Mandalay region, Sagaing region, Bago region, and Mon state. Figure 1 shows the locations of all study sites, the number of people participating in this study and number of people working at each site. For example, 40 individuals were employed in the head office at the time of data collection, while 25 of them were interviewed in this study. Potential participants were the staff working in the head office and selected clinics, including medical doctors, nurses, midwives, lab technicians, cashiers/receptionists/accountants (CRAs), sexual and reproductive health promoters (SRHP), and program staff members.

\section{Theoretical Framework}

The proposed theoretical framework comprises technical

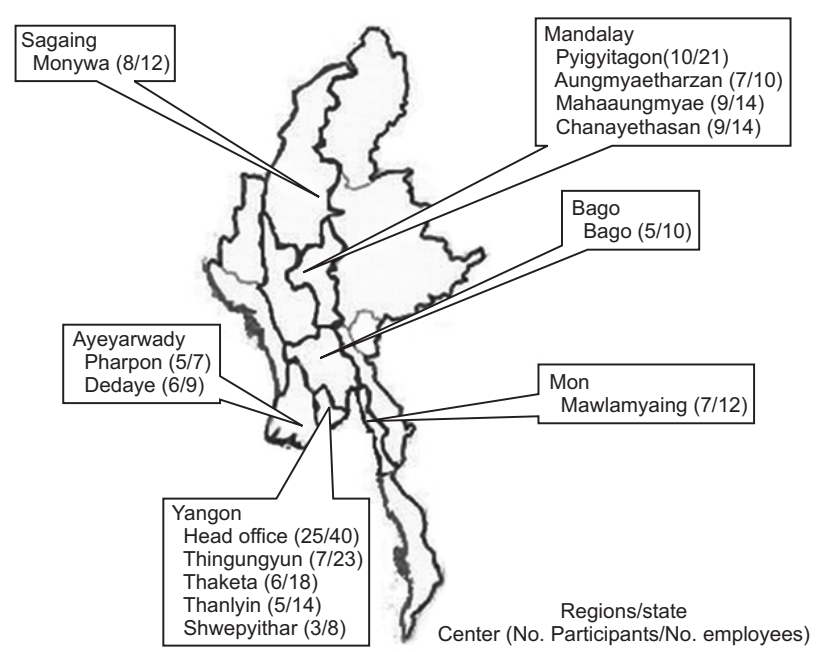

Figure 1. Locations where questionnaire survey was conducted. 
feasibility and user acceptance of the proposed system as shown in Figure 2. To determine technical feasibility, the staff computer usage, technology availability, and network availability at the MSI-M clinic/offices were assessed through a questionnaire survey adapted from a previous national survey in Thailand [12]. User acceptance of the EMR system was assessed based on the TAM introduced by Davis [13].

\section{Questionnaire}

The structured questionnaire comprised information at two levels, the organization and the individual. At the organization level, there were 8 questions on technological availability and network availability at work, such as the availability of computer systems, type of software, Internet availability, service providers, means of accessing the Internet, number of people working at the clinic/office, and number of people routinely using computers. The information on the technology and network availability of the clinic was obtained from one appropriate position, such as the supervisor/doctor of the respective clinic.

At the individual level, there were four sections including (A) individual demographic, (B) user acceptance (perceived usefulness [PU] and perceived ease of use [PEOU]), (C) ICT knowledge, and (D) computer usage. The survey questions were initially developed in English, and the translation-backtranslation method was used.

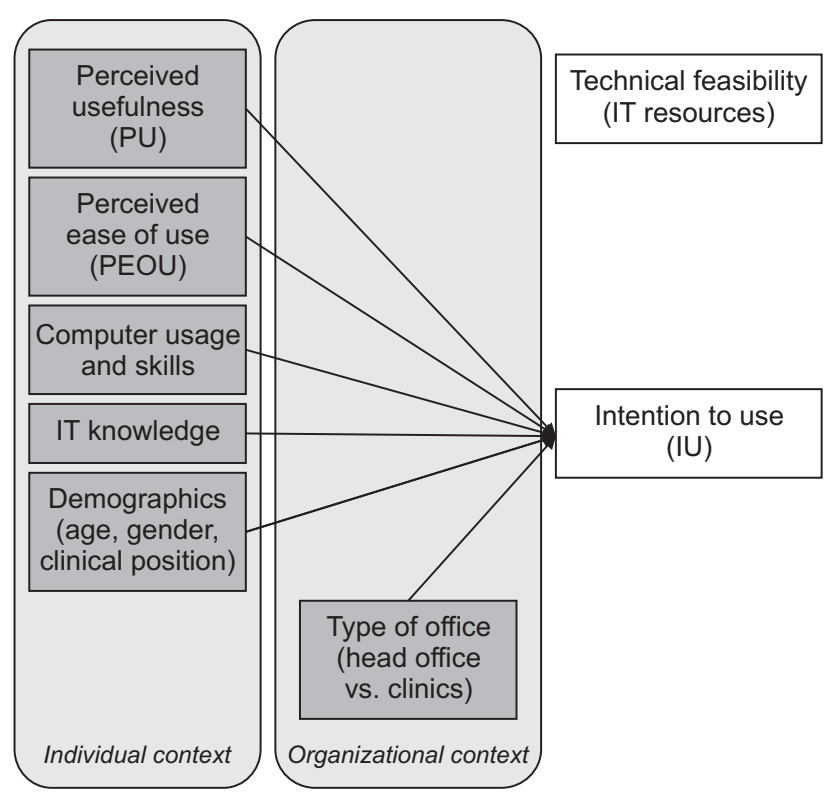

Figure 2. Adapted theoretical TAM (technology acceptance model) model.

\section{1) Section A: Demographic information}

The demographic information included age, gender, education, position held at the MSI-M, work experience in healthcare, and work experience in the MSI-M clinic/office.

\section{2) Section B: User acceptance}

Based on the TAM model [13], three main components were assessed, namely, PU, PEOU, and intention to use (IU). Four items were used to assess PEOU, 7 items were used to assess the PU, and the rest were for IU assessment. Respondents were asked to indicate their agreement with each item on a 5 -point numerical scale, ranging from 1 (meaning strongly disagree) to 5 (meaning strongly agree).

\section{3) Section C: Information communications technology knowledge}

Basic ICT knowledge was assessed using ten true/false statements guided by the European Computer Driving License (ECDL) basic IT sample test and by a study of computer literacy in US university freshmen [12]. The statements were related to basic knowledge, such as operating systems, software, viruses, printers, networks, the Internet, and so forth. Three choices were given as an answer to each statement, i.e., True, False, and Not Know. Only a correct answer was given a score of one. The average score was used as a cut-off for two groups, i.e., low and high knowledge levels.

\section{4) Section D: Computer usage}

The participants' experience of computer usage was assessed based on 5 questions, including how long they have been using it, how often they use it, what kind of computer they use, what kind of activities they do with computers, and what kind of training and experience with computers they have previously. In addition to participants' experience, a set of 10 activities were given to the participants to rate the frequency of performing such activities from 0 (never perform this task) to 3 (always use a computer). The 10 activities could further be classified into three categories: (1) providing care and reporting usage (these activities comprised recording a patient's general and specific data, retrieving the patient clinical record, and generating a mandatory report), (2) administrative usage (these included writing official letters, analyzing data, and preparing presentation slides), and (3) communication usage (communicating with colleagues, searching for information associated with office tasks, and searching for information associated with personal interest) [12]. 


\section{Statistical Analysis}

The number and percentage of samples were used to describe count/frequency data while mean and standard deviation (SD) or median and range, depending on data distribution, were used to describe the demographics of the sampled population and the scores of each section. An independent t-test was conducted to compare these characteristics by type of office and by site, respectively. Pearson correlation test was conducted to explore the relationships between user acceptance variables, including PU, PEOU, IU, and external factors, including computer usage and ICT knowledge scores. To assess the factors influencing the IU the new system, logistic regression was applied. The outcome in terms of the IU was made binary based on the mean score being the cut-off value. The analyses were performed using SPSS software version 19 (IBM SPSS, Armonk, NY, USA).

\section{Ethical Considerations}

Ethics approval for this research was received from both the Mahidol University Ethical Committee and the MSIM Internal Committee, together with a permission letter to conduct the survey from the country director of MSI-M (IRB No. MUTM 2013-073-01). All participants volunteered to participate and were not paid for interviews.

\section{Results}

\section{Demographics Information}

The general characteristics of the respondents working at MSI-M are presented in Table 1. Of all participants, $81.2 \%$ were female and $18.8 \%$ were male. The mean age of the participants was $35.06 \pm 9.5$ years, with the youngest age of 22 and oldest age of 63. Regarding education level, the majority of the respondents had graduated with a bachelor's degree (74.1\%). Most of the participants were non-clinical staff members (69.6\%), including CRAs, SRHPs, counsellors, supervisors, managers, and administrators. In response to the working experience in healthcare, the majority (50.9\%) of the participants had been working in healthcare for more than 6 years, followed by $4-6$ years representing $28.6 \%$. As for working at the respective clinics or head office, $38.4 \%$ of the survey respondents had worked at the clinic/office for more than 6 years, 33\% for 4-6 years, and 1-3 years represented $18.8 \%$ (data not shown).

\section{Technical Feasibility}

As for the technical feasibility assessment, at the time of the survey, all surveyed MSI-M clinics and head office were
Table 1. Demographics description

\begin{tabular}{lccc}
\hline \multicolumn{1}{c}{ Characteristic } & $\begin{array}{c}\text { Head office } \\
(\mathrm{n}=25)\end{array}$ & $\begin{array}{c}\text { Other } \\
(\mathrm{n}=87)\end{array}$ & $\begin{array}{c}\text { Total } \\
(\mathrm{n}=112)\end{array}$ \\
\hline Sex & $8(32.0)$ & $13(14.9)$ & $21(18.8)$ \\
$\quad$ Male & $17(68.0)$ & $74(85.1)$ & $91(81.2)$ \\
Female & & & \\
Age (yr) & $4(16.0)$ & $45(51.7)$ & $49(43.8)$ \\
$<30$ & $10(40.0)$ & $26(29.9)$ & $36(32.1)$ \\
$31-40$ & $8(32.0)$ & $12(13.8)$ & $20(17.9)$ \\
$41-50$ & $3(12.0)$ & $4(4.6)$ & $7(6.3)$ \\
$>50$ & & & $10(8.9)$ \\
Education level & $8(32.0)$ & $2(2.3)$ & $83(74.1)$ \\
Master & $17(68.0)$ & $66(75.9)$ & $2(1.8)$ \\
Bachelor & - & $2(2.3)$ & $17(15.2)$ \\
Diploma & - & $17(19.5)$ & \\
High School & $6(24.0)$ & $28(32.2)$ & $34(30.4)$ \\
Position & $19(76.0)$ & $59(67.8)$ & $78(69.6)$ \\
Clinical & & & \\
Non-clinical & & & \\
\hline
\end{tabular}

Values are presented as number (\%).

equipped with computers. However, the number of available computers ranged from 1 to 36 per site depending on the size of the clinic and office. A server was installed only at the head office. The total number of personnel working at the surveyed clinics and office was 212, of which 89 had routinely used a computer. Microsoft Office was used by staff members at all clinics. Approximately $27 \%$ of the respondents stated that analytical tools like SPSS had been installed, and 22.3\% had both Internet service and an email system installed. Methods of Internet access by the participants varied; the majority, $45.5 \%$ used Internet cafés, $20.5 \%$ only accessed the Internet at home, and $22.3 \%$ accessed the Internet from their office using an asymmetric digital subscriber line (ADSL) or a paid Internet service provider (ISP), such as Red Link. On the other hand, $2.7 \%$ stated that they had never accessed the Internet.

\section{Computer Usage}

Table 2 represents the mean score on computer usage at the clinics in the head office and MSI-M clinics. Ten activities regarding computer usage were categorized into three groups including four activities related to care providing and reporting, three activities on administration, and three activities on communication. The score was used to measure the frequency of the activities. Computer usage in terms of providing 
care and reporting was relatively low in every regional clinic. A high level of computer usage in all components, i.e., providing care and reporting, administration and communication, was found in the head office compared to other regions or state. Using an independent t-test, the computer usage of the head office and the clinics differed significantly in terms of administration usage $(p<0.01)$ and communication usage $(p<0.01)$.

\section{Information Communications Technology Knowledge}

As seen in Table 2, there was significantly better knowledge among the head office staff compared to the rest $(p=0.015)$. Overall, the mean score on knowledge of the staff at the head office was the highest, and the clinics in the Ayeyarwady region had a relatively lower score on IT knowledge compared to the rest (Table 3). There were significant differences in ICT knowledge between different regions/states (Table 3) and between different job descriptions (data not shown).

\section{User Acceptance Measures}

The mean and SD of PEOU, PU, and IU of the clinics and the head office were shown in Table 4. Independent t-test results showed the scores for all items measured differed among the study sites. There were significant differences in

Table 2. Computer usage and IT knowledge scores from the head office and the MSI-M clinics

\begin{tabular}{lccc}
\hline \multirow{2}{*}{\begin{tabular}{c} 
Measurable items \\
\cline { 2 - 3 }
\end{tabular}} & $\begin{array}{c}\text { Head office } \\
(\mathrm{n}=25)\end{array}$ & $\begin{array}{c}\text { Other } \\
(\mathrm{n}=\mathbf{8 7})\end{array}$ & \\
\hline Computer usage & & & \\
$\begin{array}{c}\text { Providing care and } \\
\text { reporting (12 marks) }\end{array}$ & $5.64 \pm 2.93$ & $5.06 \pm 2.02$ & 0.387 \\
$\begin{array}{c}\text { Administration (9 marks) } \\
\text { Communication (9 marks) }\end{array}$ & $8.60 \pm 0.71$ & $5.31 \pm 2.48$ & $<0.01$ \\
Knowledge (out of 10) & $7.96 \pm 1.79$ & $4.00 \pm 2.77$ & $<0.01$ \\
\hline
\end{tabular}

Values are presented as mean \pm standard deviation. all scores between the head office and the clinics, where all scores were lower among the staff working at the head office. There were significant differences in IU between different geographic regions (Table 5) and different job descriptions (data not shown). The staff members working in the Yangon, Mandalay, and Ayeyarwady regions had relatively high IU scores compared with other regions or states. The staff working in the head office and management administration staffs were more reluctant to use the proposed system compared to other regions and job descriptions.

As presented in Table 6, there were significant positive relationships between PU and PEOU $(r=0.701, p<0.01)$, PU and IU $(r=0.846, p<0.01)$, and PEOU and IU $(r=0.627$, $p<0.01)$. The results of the final logistic regression after backward stepwise selection using the likelihood-ratio statistic as the criteria for removing variables are shown in Table 7. In the final model, the LR statistic was 35.048. According to the final model, the factors influencing the IU the proposed system were $\mathrm{PU}$ (odds ratio $[\mathrm{OR}]=5.05, p<0.01$ ), and being head office staff $(\mathrm{OR}=0.07, p<0.05)$. Not surprisingly, the perception of usefulness significantly influenced the desire to use EMR (more than 5 times) in our study. On the other hand, the staff from the head office expressed much less desire to implement an EMR system. In fact, they were more than 10 times less likely to express desire to implement such a system in comparison with staff from the other offices.

Table 4. Results on user acceptance from the head office and the MSI-M clinics

\begin{tabular}{lccc}
\hline \multirow{2}{*}{ User acceptance measures } & \multicolumn{2}{c}{ Study sites } & \\
\cline { 2 - 3 } & $\begin{array}{c}\text { Head office } \\
(\mathrm{n}=\mathbf{2 5})\end{array}$ & $\begin{array}{c}\text { Other } \\
(\mathrm{n}=\mathbf{8 7})\end{array}$ & $p$-value \\
\hline Perceived ease of use (PEOU) & $3.77 \pm 0.60$ & $4.26 \pm 0.46$ & $<0.01$ \\
Perceived usefulness (PU) & $3.68 \pm 0.97$ & $4.22 \pm 0.58$ & 0.012 \\
Intention to use (IU) & $3.82 \pm 0.41$ & $4.09 \pm 0.48$ & 0.014 \\
\hline
\end{tabular}

Values are presented as mean \pm standard deviation.

MSI-M: Marie Stopes International Myanmar.

Table 3. ICT knowledge in head office, regions, and state

\begin{tabular}{|c|c|c|c|c|c|c|c|c|c|}
\hline & $\begin{array}{c}\text { Total } \\
(\mathrm{n}=109)\end{array}$ & $\begin{array}{l}\text { Head office } \\
\qquad(n=25)\end{array}$ & $\begin{array}{l}\text { Mandalay } \\
(\mathrm{n}=33)\end{array}$ & $\begin{array}{c}\text { Sagaing } \\
(n=7)\end{array}$ & $\begin{array}{c}\text { Bago } \\
(n=5)\end{array}$ & $\begin{array}{c}\text { Ayeyarwady } \\
(\mathrm{n}=11)\end{array}$ & $\begin{array}{l}\text { Yangon } \\
(n=21)\end{array}$ & $\begin{array}{c}\text { Mon } \\
(n=7)\end{array}$ & $n-$ s. \\
\hline Knowledge scor & $7.21 \pm 1.76$ & $7.96 \pm 1.71$ & $7.45 \pm 1.56$ & $7.43 \pm 1.13$ & $7.00 \pm 2.55$ & $4.91 \pm 1.22$ & $7.43 \pm 1.13$ & $6.29 \pm 1.11$ & $<0.001$ \\
\hline
\end{tabular}

Values are presented as mean \pm standard deviation.

ICT: information communications technology.

Measurement scale: Right Answer $=1$, Wrong Answer $=0$, Not Know $=0$.

${ }^{a}$ ANOVA test. 
Table 5. User acceptance score in head office, regions, and state

\begin{tabular}{lccccccccc}
\hline & $\begin{array}{c}\text { Total } \\
(\mathrm{n}=111)\end{array}$ & $\begin{array}{c}\text { Head office } \\
(\mathrm{n}=\mathbf{2 5})\end{array}$ & $\begin{array}{c}\text { Mandalay } \\
(\mathrm{n}=\mathbf{3 4})\end{array}$ & $\begin{array}{c}\text { Sagaing } \\
(\mathrm{n}=\mathbf{8})\end{array}$ & $\begin{array}{c}\text { Bago } \\
(\mathrm{n}=\mathbf{5})\end{array}$ & $\begin{array}{c}\text { Ayeyarwady } \\
(\mathrm{n}=11)\end{array}$ & $\begin{array}{c}\text { Yangon } \\
(\mathrm{n}=\mathbf{2 1})\end{array}$ & $\begin{array}{c}\text { Mon } \\
(\mathrm{n}=\mathbf{7})\end{array}$ & $p$-value \\
\hline PEOU & $4.03 \pm 0.47$ & $3.82 \pm 0.41$ & $4.19 \pm 0.37$ & $3.94 \pm 0.45$ & $3.65 \pm 0.28$ & $4.07 \pm 0.58$ & $4.08 \pm 0.54$ & $4.11 \pm 0.65$ & 0.046 \\
PU & $4.15 \pm 0.53$ & $3.77 \pm 0.59$ & $4.29 \pm 0.43$ & $4.09 \pm 0.49$ & $4.03 \pm 0.27$ & $4.30 \pm 0.42$ & $4.35 \pm 0.52$ & $4.20 \pm 0.54$ & 0.002 \\
IU & $4.10 \pm 0.72$ & $3.68 \pm 0.96$ & $4.31 \pm 0.54$ & $4.00 \pm 0.53$ & $4.00 \pm 0.35$ & $4.23 \pm 0.64$ & $4.26 \pm 0.64$ & $4.07 \pm 0.73$ & 0.034 \\
\hline
\end{tabular}

Values are presented as mean \pm standard deviation.

PU: perceived usefulness, PEOU: perceived ease of use, IU: intention to use.

Measurement scale: 1 = Strongly Disagree, 2 = Disagree, 3 = Neutral, 4 = Agree, 5 = Strongly Agree.

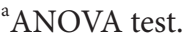

Table 6. Correlation matrix between user acceptance and external factors

\begin{tabular}{llllll}
\hline \multicolumn{1}{c}{ Variable } & PU & PEOU & IU & Usage & Knowledge \\
\hline PU & 1 & & & & \\
PEOU & $0.701^{\star *}$ & 1 & & & \\
IU & $0.846^{* *}$ & $0.627^{\star *}$ & 1 & & \\
Usage & -0.074 & 0.044 & -0.055 & 1 & \\
Knowledge & 0.059 & 0.082 & 0.131 & 0.185 & 1 \\
\hline
\end{tabular}

PU: perceived usefulness, PEOU: perceived ease of use, IU: intention to use.

${ }^{* *} p<0.01$ for Pearson correlation test.

\section{Discussion}

The survey showed that all the clinics were currently equipped with at least one computer, whereas a server was available only at the head office. Limited ICT availability was in line with the current Myanmar ICT infrastructure. According to the International Telecommunication Union, Myanmar ranked 135th out of 176 nations in the Network Readiness Index 2017, indicating the low ICT development of the country [14]. Concerns about the lack of infrastructure for stable power supply and Internet access in Myanmar and other lower income countries in the region have been reported previously by Lewis et al. [15].

EMR system deployment increases the quality of healthcare services [16] as well as physicians' satisfaction [17]. However, implementing such systems is never easy while taking into account baseline data, such as who will be the users, their ICT knowledge, and their acceptance towards the system. Low level of computer usage was found in both the head office and other clinics because every center uses a paper-based record system. This can be explained by the participants' satisfaction with the paper-based record system in terms of familiarity, flexibility, and portability as reported
Table 7. Results of the logistic regression

\begin{tabular}{lccc}
\hline \multicolumn{1}{c}{ Independent variables } & OR & $95 \% \mathrm{Cl}$ & $p$-value \\
\hline Perceived usefulness (PU) & 5.050 & $(2.386-10.689)$ & $<0.01$ \\
ICT knowledge $^{2}$ & 2.196 & $(0.976-4.942)$ & 0.057 \\
Head office $^{\mathrm{a}}$ & 0.066 & $(0.005-0.966)$ & 0.047 \\
Clinical position $^{\mathrm{b}}$ & 5.838 & $(0.649-52.548)$ & 0.116 \\
\hline
\end{tabular}

OR: odds ratio, CI: confidence interval, ICT: information communications technology.

${ }^{a}$ Where non-head office was treated as the baseline, i.e., $\mathrm{OR}=1$. ${ }^{\mathrm{b}}$ Where non-clinical position was treated as the baseline, i.e., $\mathrm{OR}=1$.

in a previous study in Myanmar [18]. The high level of computer usage in the head office compared with other regions or states may be attributed to the higher number of staff members working at the head office (see Figure 1) compared with the other clinics. A previous study also found that the number of staff members was a significant factor associated with high technology use in the clinics [19].

Doctors, managers, and administrators had high levels of ICT knowledge owing to the nature of their jobs in the organization. A significant difference in knowledge level between different regions/states was mainly due to one region, Ayeyarwady, because staff working in that region had a significantly lower knowledge level compared with those of all the other regions/states (data not shown). Differences in knowledge level pose a challenge for implementing an EMR system in MSI-M. The majority of the respondents have had some computer-related training, but very few people had an IT background. Because a lack of skilled manpower was identified as a common barrier in implementation of EMR systems in developing countries [20,21], more computer training will help improve ICT knowledge and facilitate the future implementation of an EMR system.

The positive responses on PU (average score $=4.15$ out 
of 5), PEOU (average score $=4.03$ out of 5), and IU (average score $=4.10$ out of 5 ) reflect a positive perception of the EMR system. The lowest score in users' PEOU indicated the users' unfamiliarity with the EMR system. Results of a correlation analysis revealed significant positive relationships between PU, PEOU, and IU of EMRs (Table 4), which is consistent with several studies on EHR acceptance [13,22-24].

User acceptance varied from one region to another, and the head office score was the lowest in all three aspects, whereas the regions of Yangon, Mandalay, and Ayeyarwady had high IU scores. The lowest user acceptance scores and relatively lower IU of EMR among the head office staff were due to the fact that they were not working in the clinical fields where the real benefit of using EMR to process real-time patient data analytically would be. The additional qualitative study in the same population suggested that one main perceived challenge around the proposed system raised by clinicians and head office staff was the sustainability of the proposed EMR under the current situation in Myanmar [9]. Moreover, being the largest among all MSI-M offices in Myanmar, the head office could also face organizational resistance to change compared with the other smaller MSI-M regional clinics [25].

Interestingly, the high IU score among the staff at the Ayeyarwady regional clinic despite their low IT knowledge can be explained by their increased demand for efficiency of clinical practice at their clinics because they had the lowest number of staff members (Figure 1) among all MSI-M clinics in Myanmar. This concept is supported by a previous study at a UK hospital in which they found that increased pharmacist efficiency at the hospital was achieved after implementation of an electronic prescribing system at the hospital [26]. Similar to a recent study among dental professionals in Myanmar [18], the participants in this study had a high level of IU the proposed system although they had a low level of health IT usage. The limitation of this study was that it included only 13 out of 25 regional clinics in Myanmar due to limitations of budget and time to travel to all regional clinics in Myanmar. Therefore, generalization of the results should be considered carefully since the study did not cover all of the MSI-M clinics in Myanmar. In addition, only $30.4 \%$ of the surveyed subjects in our study were clinical staff members who would be the major users of EMRs at MSI-M.

The success of health IT relies on end-user' acceptance and IU the proposed IT. Given the high IU the EMR system at the clinics, the vision of deploying an EMR system in MSI$\mathrm{M}$ to improve patient care and achieve more effective data management is not far-fetched. Realizing this vision will require major effort to overcome the users' concerns and other prevailing factors, such as the current technology infrastructure of the country and potential user's familiarity with the technology. In addition, a strong leadership role in mandating the clinics to deploy such system and training the employees is essential. Involving users at all level in the initial implementation stage can increase the acceptance of the EMR system.

\section{Conflict of Interest}

No potential conflict of interest relevant to this article was reported.

\section{Acknowledgments}

The authors would like to thank the study participants at MSI-M and all staff from the Department of Tropical Hygiene for their support. The study was funded by the Faculty of Tropical Medicine, Mahidol University and the WellcomeTrust Major Overseas Programme in South East Asia (No. 106698/Z/14/Z).

\section{ORCID}

Win Min Thit (http://orcid.org/0000-0002-2362-5068)

Sai Wai Yan Myint Thu (http://orcid.org/0000-0002-7174-7481) Jaranit Kaewkungwal (http://orcid.org/0000-0001-7916-8460) Ngamphol Soonthornworasiri (http://orcid.org/0000-0003-1031-7979) Nawanan Theera-Ampornpunt (http://orcid.org/0000-0002-3322-4145) Boonchai Kijsanayotin (http://orcid.org/0000-0001-8932-1086) Saranath Lawpoolsri (http://orcid.org/0000-0003-4841-7924) Sid Naing (http://orcid.org/0000-0003-1638-1410)

Wirichada Pan-ngum (http://orcid.org/0000-0002-9839-5359)

\section{References}

1. Kruse CS, Kothman K, Anerobi K, Abanaka L. Adoption factors of the electronic health record: a systematic review. JMIR Med Inform 2016;4(2):e19.

2. Organisation for Economic Cooperation and Development. Health at a Glance: Europe 2018: State of Health in the EU Cycle. Paris, France: Organisation for Economic Cooperation and Development; 2018.

3. Hoyt RE, Sutton M, Yoshihashi A. Medical informatics: practical guide for the healthcare professional. Pensacola (FL): University of West Florida; 2009. 
4. Aldosari, B. Patients' safety in the era of EMR/EHR automation. Informatics in Medicine Unlocked 2017;9: 230-3.

5. Cook-Moine C, Cramer L. Financial savings from an electronic medical record in a small group practice. Chicago (IL): Healthcare Information and Management Systems Society Inc; 2018.

6. Alpert JS. The electronic medical record in 2016: Advantages and disadvantages. Digit Med 2016;2(2):48-51.

7. Evans RS. Electronic health records: then, now, and in the future. Yearb Med Inform 2016;Suppl 1(Suppl 1): S48-61.

8. Kruse CS, Kristof C, Jones B, Mitchell E, Martinez A. Barriers to electronic health record adoption: a systematic literature review. J Med Syst 2016;40(12):252.

9. Thit WM, Kaewkungwal J, Soonthornworasiri N, Theera-Ampornpunt N, Kijsanayotin B, Lawpoolsri S, et al. Electronic medical records in Myanmar: user perceptions at Marie Stopes International Clinics in Myanmar. Southeast Asian J Trop Med Public Health 2016; 47(4):799-809.

10. Watkinson-Powell A, Lee A. Benefits of an electronic medical records system in rural Nepal. JNMA J Nepal Med Assoc 2012;52(188):196-200.

11. Marie Stopes International. Where in the world, Myanmar [Internet]. London, UK: Marie Stopes International; c2020 [cited at 2020 Jul 25]. Available from: http://www. mariestopes.org/where-in-the-world\#myanmar.

12. Kijsanayotin B, Speedie S. Are health centers in Thailand ready for health information technology? A national survey. AMIA Annu Symp Proc 2006;2006:424-8.

13. Davis FD. Perceived usefulness, perceived ease of use, and user acceptance of information technology. MIS Q 1989;13(3):319-340.

14. Htun KS. An investigation of ICT development in Myanmar. Electron J Inf Syst Dev Ctries 2019;85(2):e12068.

15. Lewis T, Synowiec C, Lagomarsino G, Schweitzer J. Ehealth in low- and middle-income countries: findings from the Center for Health Market Innovations. Bull World Health Organ 2012;90(5):332-40.

16. Ayaad O, Alloubani A, ALhajaa EA, Farhan M, Abuseif S, Al Hroub A, et al. The role of electronic medical records in improving the quality of health care services: Comparative study. Int J Med Inform 2019;127:63-7.

17. Gidwani R, Nguyen C, Kofoed A, Carragee C, Rydel T, Nelligan I, et al. Impact of scribes on physician satisfaction, patient satisfaction, and charting efficiency: a randomized controlled trial. Ann Fam Med 2017;15(5):42733.

18. Thu SW, Kijsanayotin B, Kaewkungwal J, Soonthornworasiri N, Pan-Ngum W. Satisfaction with paper-based dental records and perception of electronic dental records among dental professionals in Myanmar. Healthc Inform Res 2017;23(4):304-13.

19. van der Zande MM, Gorter RC, Aartman IH, Wismeijer D. Adoption and use of digital technologies among general dental practitioners in the Netherlands. PLoS One 2015;10(3):e0120725.

20. Afrizal SH, Hidayanto AN, Handayani PW, Budiharsana M, Eryando T. Narrative review for exploring barriers to readiness of electronic health record implementation in primary health care. Healthc Inform Res 2019;25(3):14152.

21. Muinga N, Magare S, Monda J, English M, Fraser H, Powell J, et al. Digital health systems in Kenyan Public Hospitals: a mixed-methods survey. BMC Med Inform Decis Mak 2020;20(1):2.

22. San AN, Yee CJ. The modified technology acceptance model for private clinical physicians: a case study in Malaysia, Penang. Int J Acad Res Bus Soc Sci 2013;3(2):380403.

23. Dünnebeil S, Sunyaev A, Blohm I, Leimeister JM, Krcmar H. Determinants of physicians' technology acceptance for e-health in ambulatory care. Int J Med Inform 2012;81(11):746-60.

24. Aggelidis VP, Chatzoglou PD. Using a modified technology acceptance model in hospitals. Int J Med Inform 2009;78(2):115-26.

25. Lorenzi NM, Riley RT. Organizational issues = change Int J Med Inform 2003;69(2-3):197-203.

26. Bevan A, Patel N. An electronic prescription alerting system-improving the discharge medicines process. Arch Dis Child 2016;101(9):e2. 